\section{Acute anaphylaxis, pulmonary oedema, and intravascular haemolysis due to cryoprecipitate}

Cryoprecipitate or other plasma products are being used with increasing frequency in the treatment of haemophilia, so that Rizza and Biggs (1971) estimated that the blood from 90,000 donations was used in 1970 . Severe reactions to cryoprecipitate are extremely rare but have been described by Maycock et al. (1963), Ahrons et al. (1970), and Rizza and Matthews (1972). The severity of the immediate reaction in the patient reported here brought him very near death, and we therefore thought it should be reported.

\section{Case report}

The patient was a $5 \frac{1}{2}$-year-old boy with classical haemophilia (Factor VIII deficiency) diagnosed when 1 year old. Since that time he had received a total of 21 intravenous injections of cryoprecipitate.

In December 1971 he was seen with a haemarthrosis of the left knee and multiple ecchymoses over both legs. It was decided to give cryoprecipitate, which was drawn into a $30 \mathrm{ml}$ syringe and given intravenously. After 10 $\mathrm{ml}$ had been given, the patient started to cough, and after a further $5 \mathrm{ml}$, he became pale, sweaty, and shocked, and stated that he thought he was going to die. His peripheral pulses were impalpable and the blood pressure could not be recorded. Chlorpheniramine $10 \mathrm{mg}$ and hydrocortisone $100 \mathrm{mg}$ were given intravenously with some improvement, so that his blood pressure was then recorded. His respirations were rapid with marked recession and central cyanosis. He coughed up large quantities of pink, frothy sputum, and had many fine râles throughout his chest. An $x$-ray confirmed the presence of pulmonary oedema. He was given frusemide $10 \mathrm{mg}$ immediately and hydrocortisone 100 mg intravenously every 6 hours. Two hours after the injection he developed haemoglobinuria which persisted for 16 hours. His bilirubin was $2.8 \mathrm{mg} / 100 \mathrm{ml}$, and methaemalbumin was present in the serum. Within 24 hours of the injection he had improved dramatically and his chest $x$-ray was normal. In 48 hours he appeared to be completely normal.

In the past this boy had responded once to a bee sting by developing swelling of the face and coughing within 5 minutes. This subsided rapidly with oral chlorpheniramine. Subsequently he has had two bee stings without reaction.

It is clear that this patient developed acute anaphylactic shock, pulmonary oedema, and intravascular haemolysis as a result of $15 \mathrm{ml}$ cryoprecipitate. The cryoprecipitate came from 4 donors, 3 of whom were group $O R h$ positive (donors $P, L$, and $R$ ) and 1 group $A B R h$ positive (donor $\mathrm{Y}$ ). In order to discover the cause of this reaction the following investigations were carried out. (1) $C^{\prime} 4$ complement measured as $\beta 1 \mathrm{E}$ immediately after the reaction was very low $(10.4 \mathrm{mg} / 100 \mathrm{ml})$ suggesting some involvement of complement in the reaction. C'3 was normal. (2) Culture of cryoprecipitate was sterile. (3) Direct antiglobulin test was negative. (4) No white cell antibodies or irregular red cell antibodies could be shown in the patient's serum. (5) Patient had anti-Gm2 in his serum but in none of the donors was $\mathrm{Gm} 2$ present. (6) No anti-IgA could be shown in the patient's serum. (7) No incompatibility could be shown by immunodiffusion between sera from the donors and serum from the patient. (8) Cryoprecipitate from pooled donors $\mathrm{Y}$ and $\mathrm{P}$ had strong anti-A with weak anti-B. That from pooled donors $L$ and $R$ had weak anti-A and weak anti-B. (9) Donor $P$ had strong immune anti-A agglutinins with $\mathrm{IgG}$ and IgM components: this anti-A was difficult to neutralize with AB serum. (10) Blood group of the patient was $A_{2} B$ Rh negative with less than average $A$ substance in his serum. (11) Donor L had a severe bee sting 9 weeks before blood donation. (12) Patient's skin test to bee sting extract was positive, but with no systemic disturbance. (13) Patient's serum IgE was 500 units $/ \mathrm{ml}$, a slightly raised level. Though this suggested he is a reaginic subject, passive cutaneous anaphylaxis, using the patient's serum and the residue of the cryoprecipitate injected into the father's skin, was negative.

After this episode it was decided that cryoprecipitate for this child would be specially prepared from donors of group $A$ with weak anti-B, or group $A B$ and $G m 2$ negative. Before each injection a prick skin test is carried out on the first bottle of cryoprecipitate. Hydrocortisone $100 \mathrm{mg}$ and chlorpheniramine $10 \mathrm{mg}$ are given intravenously. Each bottle is given separately over 15 minutes and each subsequent bottle is skin tested and given 30 minutes later. With this regimen he received two treatments with cryoprecipitate without ill effects and has now received another two without any drugs or skin testing and without any reaction.

\section{Discussion}

As far as we have discovered, there are two possible sources of this child's severe reaction to cryoprecipitate. The plasma of donor $\mathrm{L}$ may have contained some bee sting protein, or the immune anti-A from donor $\mathbf{P}$ may be responsible. Though there is clear evidence that the patient was sensitive 
to bee stings, it seems unlikely that donor L's serum would contain sufficient foreign protein 9 weeks after a bee sting for this reaction. There was also no demonstrable incompatibility between the serum from donor $\mathrm{L}$ and the patient by immunodiffusion.

Although the intravascular haemolysis could well have been due to a reaction between transfused anti- $A$ from donor $P$ and the patient's $A_{2} B$ red cells, severe anaphylaxis and pulmonary oedema are not characteristic of $\mathrm{ABO}$ incompatibility. The present case is, however, very similar to that described by Mollison (1967) when large quantities of strong anti-A plasma had been injected to a group $A_{1}$ recipient. Neither of these two conditions applies in this case, for our patient is group $\mathrm{A}_{2} \mathrm{~B}$ and only 3 to $4 \mathrm{ml}$ of pooled cryoprecipitate injected would have come from the donor with high titre immune anti-A. This anti-A was difficult to neutralize with $\mathrm{AB}$ serum. However, since excluding anti-A from the cryoprecipitate used in this child, no reactions have occurred on four occasions. Maycock et al. (1963) have pointed out that reactions appear to be related both to the individual patient and the specific preparation of antihaemophilic globulin.

The anaphylactic shock in our patient was similar to that produced sometimes with $\gamma$-globulin (Barandun et al., 1962), but this reaction would not be responsible for the intravascular haemolysis. Severe reactions from transfused plasma have been described due to IgA incompatibility (Vyas, Perkins, and Fudenberg, 1968; Schmidt, Taswell, and Gleich, 1969; Miller et al., 1970) and Gm incompatibility (Fudenberg et al., 1964; Fischer, 1965; Jensen, Gürtler, and Bruusgaard, 1968; Prentice et al., 1971), but both these causes were eliminated here. Eisen (1965) found levels of kinin-forming activity and of $\mathrm{C}^{\prime} 1$-esterase in Factor VIII-rich fractions of fresh plasma and the quantity was sufficient to produce side effects during transfusions. All tested batches had a similar potency for both these enzymes, so he suggested that the factor determining whether the patient has a reaction or not is the capacity of the patient's blood to inactivate these enzymes and the rate of inactivation is dependent upon the speed of the injection. Maycock et al., (1963) have shown that reactions are less frequent when the injection is given slowly. We have not investigated this mechanism fully, but it is interesting to note that the level of C'1-esterase inhibitor in the cryoprecipitate used was found to be at the upper limit of the normal range.

\section{Conclusion}

All physicians treating patients suffering from haemophilia should be aware that severe reactions may occur and be prepared for them, and perhaps be less enthusiastic in using cryoprecipitate for relatively trivial bleeding than in the past. It appears that the haemoglobinuria and bilirubinaemia in our patient might have been due to the high titre anti- $\mathrm{A}$ in spite of it being mixed with group $A B$ donor plasma. The anaphylactic shock might have been due to the rapid injection allowing the enzymes to form kinins in the patient. It would, therefore, be wise (a) always to give injections slowly, particularly if there is a previous history of hypersensitivity, and (b) to avoid giving a group A recipient high titre anti-A cryoprecipitate even when it is mixed with cryoprecipitate from a group $A$ donor. With these precautions, we have seen no reaction in a further four injections.

\section{Summary}

A haemophiliac boy developed acute anaphylaxis and pulmonary oedema while receiving an injection of cryoprecipitate. Two hours later he developed haemoglobinuria. Investigations showed these reactions might have been due to a high titre of anti-A in the plasma of one of the donors or to the formation of kinins due to the rapid injection. Slow injection of the cryoprecipitate and the avoidance of donors with a high anti-A titre are recommended.

We are grateful to the scientific and technical staff of the South West Regional Transfusion Centre and the Department of Child Health, University of Bristol, for help with many of the investigations; to Dr. K. L. G. Goldsmith (Blood Group Reference Laboratory, London) for $\mathrm{Gm}$ tests and to Dr. L. Rivat (Centre Departemental de Tranfusion Sanguine, Rouen) for IgA tests.

\section{REFERENCES}

Ahrons, S., Glavind-Kristensen, S., Drachmann, O., and KissmeyerNielsen, F. (1970). Severe reactions after cryoprecipitated human factor VIII. Vox Sanguinis, 18, 182.

Barandun, S., Kistler, P., Jeunet, F., and Isliker, H. (1962). Intravenous administration of human gamma globulin. Vox Sanguinis, 7, 157.

Eisen, V. (1965). Studies of fibrinogen fractions isolated from human plasma by precipitation with cold ether. II. Enzymic activities resembling plasma kallikrein and C'1-esterase. British fournal of Haematology, 11, 576.

Fischer, K. (1965). Immunhämatologische und klinische Befunde bei einem Transfusionszwischenfall infolge Gm (a)-Antikörperbildung. Proceedings of the 10th Congress of the International Society for Blood Transfusion, Stockholm, 1964, p. 434. Karger, Basle.

Fudenberg, H. H., Stiehm, E. R., Franklin, E. C., Meltzer, M., and Frangione, B. (1964). Antigenicity of hereditary gamma globulin $(\mathrm{Gm})$ factors-biological and biochemical aspects. Cold Spring Harbor Symposia on Quantitative Biology, 29, 463.

Jensen, K. G., Gürtler, H., and Bruusgaard, A. (1968). Blood transfusion reaction caused by serum group incompatibility. Proceedings of the 11th Congress of the International Society for Blood Transfusion, Sydney, 1966, Part I. Blood Genetics and Physiology. Haemolytic Disease of the Newborn, p. 327. Karger, Basle. 
Maycock, W. d'A., Evans, S., Vallet, L., Combridge, B., Wolf, P., McGibbon, N., French, E. E., Wallett, L. H., Dacie, J. V., Biggs, R., Handley, D., and Macfarlane, R. G. (1963). Further experience with a concentrate containing human antihaemophilic factor. British fournal of Haematology, 9, 215.

Miller, W. V., Holland, P. V., Sugarbaker, E., Strober, W., and Waldmann, T. A. (1970). Anaphylactic reactions to IgA: a difficult transfusion problem. American fournal of Clinical Pathology, 54, 618.

Mollison, P. (1967). Blood Transfusion in Clinical Medicine, 4th ed., p. 542. Blackwell Scientific Publications, Oxford and Edinburgh.

Prentice, C. R. M., Izatt, M. M., Adams, J. F., McNicol, G. P., and Douglas, A. S. (1971). Amyloidosis associated with the nephrotic syndrome and transfusion reactions in a haemophiliac. British fournal of Haematology, 21, 305.

Rizza, C. R., and Biggs, R. (1971). Haemophilia today. British fournal of Hospital Medicine, 6, 343.

Rizza, C. R., and Matthews, J. M. (1972). Management of the haemophilic child. Archives of Disease in Childhood, 47, 451.

Schmidt, A. P., Taswell, H. F., and Gleich, G. J. (1969). Anaphylactic transfusion reactions associated with anti-IgA antibody. Nerv England Journal of Medicine, 280, 188.

Vyas, G. N., Perkins, H. A., and Fudenberg, H. H. (1968). Anaphylactoid transfusion reactions associated with anti-IgA. Lancet, 2, 312.

D. Burman, * A. K. Hodson,† C. B. S. Wood, $\ddagger$ and N. F. W. BRUETON

Bristol Royal Hospital for Sick Children and South West Regional Transfusion Centre, Bristol.

*Correspondence to Dr. D. Burman, Bristol Royal Hospital for Sick Children, Bristol BS2 8BJ.

†Present address: City Hospital, Nottingham.

fPresent address: Queen Elizabeth Hospital for Children, L.ondon E.2.

\section{Addendum}

Since this report was written, 3 haemophiliacs have been reported to develop pulmonary oedema after transfusion of fresh frozen plasma and 1 of them died. 1 received a transfusion containing white cell antibodies and another $\mathrm{Gm}$ antibodies (Kernoff et al., 1972).

REFERENCE

Kernoff, P. B. A., Durrant, I. J., Rizza, C. R., and Wright, F. W. (1972). Severe allergic pulmonary oedema after plasma transfusion. British fournal of Haematology, 23 :777

\section{Magnesium supplementation in Bartter's syndrome}

Bartter's syndrome (hypokalaemic, hypochloraemic alkalosis, normotension, growth failure, and juxtaglomerular hyperplasia) is a rare disorder with less than 25 reported cases (Sutherland $e t$ al., 1970). There appear to be two forms of this syndrome. The mild form usually has its onset after the first year of life, presenting with electrolyte imbalance, growth failure, and weakness, and markedly improves with electrolyte correction
(Beilin et al., 1967; Cannon et al., 1968; Greenberg et al., 1966). Those with the severe type have symptoms of lethargy, poor appetite, dehydration, seizures, failure to thrive from the early months of life, and usually succumb before 1 year of age (Sutherland et al., 1970; Walker, 1971). This report describes the apparent life-saving effects of magnesium supplementation in an infant with the severe form of Bartter's syndrome.

\section{Case report}

An 11-week-old Black infant was admitted because of failure to thrive. He had been the $2.62 \mathrm{~kg}$ product of a term pregnancy. His unwed mother reported her gestation and delivery to have been uncomplicated. A 4-year-old half-brother and a 15-month-old sister are healthy. He had been apathetic, eating poorly, regurgitating, and had failed to gain weight from 3 weeks of age. On admission he weighed only $2.79 \mathrm{~kg}$ with a height of $54 \mathrm{~cm}$. He was emaciated, apathetic, mildly febrile, and sweating. He showed severe muscle weakness and had essentially no head control, deep tendon reflexes were hypoactive, and there was no muscle twitching. Serum electrolytes showed him to have marked hypokalaemic, hypochloraemic alkalosis with a serum sodium $133 \mathrm{mEq} / \mathrm{l}$., potassium $2.0 \mathrm{mEq} / \mathrm{l}$. chloride $74 \mathrm{mEq} / \mathrm{l}$., total carbon dioxide $40 \mathrm{mEq} / \mathrm{l}$., and pH 7.62. The serum calcium, phosphorus, creatinine,

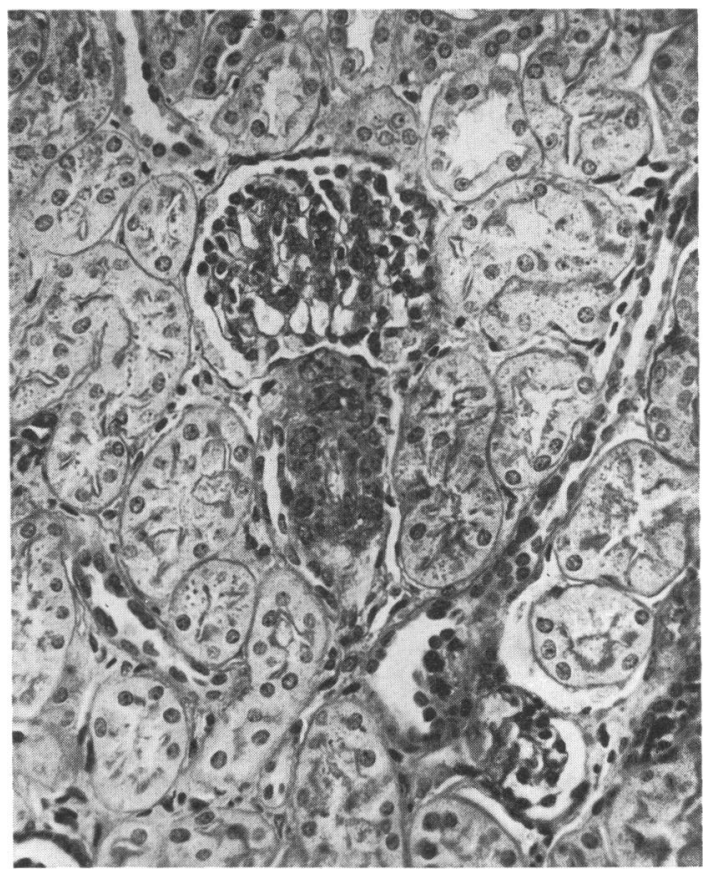

Fig.-Renal biopsy showing cloudy swelling of the proximal tubules and juxtaglomerular hyperplasia. ( $\times 129$. 